\title{
Risk Factors For Traumatic Open Fracture in Children and Adolescents Presenting With Traumatic Fractures
}

Hongwei Wang ( $\square$ cplawhw@163.com )

General Hospital of Shenyang Military Command https://orcid.org/0000-0002-2367-3465 Jun Liu

General Hospital of Northern Military Area: General Hospital of Northern Theatre command Deluo Wu

General Hospital of Northern Military Area: General Hospital of Northern Theatre command

\section{Lan Ou}

Southwest Hospital

Changqing Li

Xinqiao Hospital

Hailong Yu

General Hospital of Northern Military Area: General Hospital of Northern Theatre command

\section{Research article}

Keywords: children, adolescent, fracture, traumatic, open fracture

Posted Date: January 18th, 2021

DOl: https://doi.org/10.21203/rs.3.rs-146658/v1

License: (c) (i) This work is licensed under a Creative Commons Attribution 4.0 International License. Read Full License 


\section{Abstract}

Background: To investigate the risk factors for open fractures in children and adolescents ( $\leq 18$ years old) presenting with traumatic fractures.

Methods: We retrospectively reviewed the records of 2418 children and adolescents who presented with traumatic fractures and were admitted to our university-affiliated hospitals, among which 206 patients (8.5\%) presented with open fractures.

Results: This study enrolled 1789 males (74.0\%) and 629 females (26.0\%) with an average age of $11.2 \pm 5.0$ years. There were 206 patients $(8.5 \%)$ who presented with open fractures. The five most common fracture sites were the tibia $(31.1 \%, 64 / 206)$, fibula $(20.9 \%, 43 / 206)$, phalanx $(15.5 \%, 32 / 206)$, humerus $(11.2 \%, 23 / 206)$ and ulna $(9.7 \%, 20 / 206)$. Univariate logistic regression analysis showed that the aetiology $(P \otimes 0.001)$ and fracture site $(P \otimes 0.001)$ were risk factors for open fracture. Multivariate logistic regression analysis indicated that mechanical trauma $(\mathrm{OR}=64.229, \mathrm{P} \otimes 0.001)$, being hurt/cut by others $(\mathrm{OR}=26.757, \mathrm{P} \otimes 0.001)$, and being struck by an object $(\mathrm{OR}=15.345, \mathrm{P} \otimes 0.001)$ were stronger risk factors for open fracture than were low falls; additionally, lower limb fractures (OR=5.970, $\mathrm{P} \otimes 0.001)$, upper limb fractures $(\mathrm{OR}=5.865, \mathrm{P} \otimes 0.001)$ and multiple fractures $(\mathrm{OR}=5.414, \mathrm{P} \otimes 0.001)$ were stronger risk factors than craniofacial fractures for open fractures.

Conclusions: Aetiology (especially being injured by a machine or being hurt/cut by others) and the fracture site (including lower limb fractures, upper limb fractures and multiple fractures) were independent risk factors for open fractures.

\section{Introduction}

Fractures account for $10 \%$ to $25 \%$ of paediatric injuries ${ }^{1,2}$. The patterns of fractures vary between countries and even between regions within a country, depending on the local climate, culture, and leisuretime activities ${ }^{3-15}$. The epidemiology of open paediatric fractures is still not completely understood. The incidence varies from centre to centre; most authors agree that open fractures comprise $2 \%$ to $9 \%$ of all paediatric fractures, but the estimates vary from $0.7 \%$ to $25 \%{ }^{16-18}$. In India, researchers have reported that the incidence of open fractures was $2.8 \%$ among a total of 500 paediatric fractures ${ }^{19}$. Data about the risk factors and hospital fees for open fracture in children and adolescents ( $\leq 18$ years old) presenting with traumatic fractures are scarce.

In the present study, we reviewed a multicentre (two tertiary hospitals in Chongqing, China) database of traumatic fractures that occurred between 2003 and 2010 in a population of children and adolescents $\leq$ 18 years of age to address these deficiencies and to provide comprehensive information on this important childhood public health problem in China. The risk factors for open fracture in children and adolescents ( $\leq 18$ years old) presenting with traumatic fractures were investigated. 


\section{Materials And Methods}

\section{Study population}

Our study included 2418 patients from a population of children and adolescents ( $\leq 18$ years old) who had acute traumatic fractures between January 2003 and December 2010 and who were admitted to our university-affiliated hospitals. We used X-rays, computed tomography (CT) and magnetic resonance imaging (MRI) to make definitive diagnoses of traumatic fractures in patients who were children or adolescents ( $\leq 18$ years old). The medical records were reviewed and assessed by two independent persons who did not participate in treating any of the patients.

The patients were classified into three age groups: $\leq 6$ years old (neonatal period, infancy stage, toddler period, and preschool period), 6-12 years old (junior middle school stage) and 12-18 years old (senior high school stage). The patients were also classified into 7 groups based on the aetiology of the trauma: motor vehicle collisions (MVCs), high fall (fall from a high height $\geq 2$ m unrelated to MVCs), low fall (fall from a high height $<2 \mathrm{~m}$ unrelated to MVCs), injured by a machine, struck by an object, hurt/cut by others and other aetiology. The sites of the traumatic upper limb fractures (TULFs) were classified as the humerus, radius, ulna, clavicle, scapula and hand. The sites of the traumatic lower limb fractures (TLLFs) were classified as the femur, tibia, fibula, pelvis and foot. Nerve injuries (NIs) included central nervous system injury (traumatic brain injury and spinal cord injury) and peripheral nerve injury (cranial nerve injury and spinal nerve injury). Associated injuries (ASOls) include head injury, lung injury, renal injury, haemorrhagic shock, osteofascial compartment syndrome, retroperitoneal haematoma and so on. Complications included fracture malunion, fracture nonunion, delayed union, fracture site infection, decubitus ulcers, traumatic arthritis, deep vein thrombosis and so on. The study protocol and this manuscript were approved by the ethics committee and the institutional review board of our institution.

\section{Statistical analysis}

All statistical analyses were performed using SPSS version 22.0 (SPSS, Inc., Chicago, IL). We used Pearson chi-square tests to assess differences in age, sex distribution and clinical characteristics between the two groups of patients with and without open fractures. Continuous variables such as current age were examined using the one-sample Kolmogorov-Smirnov test for normally distributed variables; these variables are expressed as the mean \pm standard deviation (SD). Differences in the continuous variables between the two groups were evaluated using independent samples t-tests. Univariate and multivariate logistic regression analyses were used to evaluate associations between the clinicopathological features and the prevalence of open fractures.

\section{Results}

This study enrolled 1789 males (74.0\%) and 629 females (26.0\%) with an average age of $11.2 \pm 5.0$ years old. Overall, the most common aetiologies were low falls ( $n=1027,42.5 \%)$, followed by MVCs $(n=713$, $29.5 \%)$ and high falls $(n=348,14.4 \%)$. Among all the patients, the most common fracture sites were ULFs 
$(n=940,38.9 \%)$ and LLFs ( $n=758,31.3 \%)$, followed by CFFs $(n=427,17.7 \%)$ (Table 1). A total of 645 (26.7\%) patients sustained ASOls, and 200 (8.3\%) patients had experienced complications.

The etiologies such as being injured by a machine, being hurt/cut by others and being struck by object accounted for $2.0 \%$ (48/2418), 3.1\% (74/2418), 4.2\% (101/2418) (Table 1). One person (6.7\%) was injured by a machine during working in the $0-16$ age group, 30 persons $(90.9 \%)$ were injured by machine during working in the 16-18 age group. Two person (2.9\%) was struck by object during working in the 6-16 age group, 20 persons (64.5\%) were struck by object during working in the 16-18 age group. Nine person $(24.3 \%)$ was cut by others in the 6-16 age group, 15 persons (40.5\%) were cut by others in the 16-18 age group (Table 2).

There were 206 patients who presented with an open fracture: 94 patients had an open fracture on the left side (45.6\%), 105 patients had an open fracture on the right side (51.0\%), and 7 patients had open fractures on both sides (3.4\%). Overall, the most common aetiologies were MVCs ( $n=94,45.6 \%)$, followed by being injured by a machine $(n=27,13.1 \%)$. The most common fracture sites were lower extremity fractures $(114 / 206,55.3 \%)$ and upper extremity fractures $(92 / 206,44.7 \%)$. The most common fracture sites were tibial fractures $(65 / 206,31.6 \%)$, fibular fractures $(47 / 206,22.8 \%)$, radial fractures $(28 / 206,13.6 \%)$, ulnar fractures $(27 / 206,13.1 \%)$, humeral fractures $(27 / 206,13.1 \%)$, and femoral fractures $(26 / 206,12.6 \%)$. The frequencies of NIs, ASOls, and surgical treatment (ST) among the patients who presented with traumatic open fractures were significantly higher than the frequencies among patients without open fractures. The hospital stays and fees for surgical treatment for the patients who presented with traumatic open fractures were significantly higher than those for the patients without open fractures (Table 3).

Univariate logistic regression analysis showed that aetiologies (P凶0.001) and fracture sites (P凶0.001) were risk factors for open fractures (Table 1). Multivariate logistic regression analysis indicated that mechanical trauma ( $\mathrm{OR}=64.229, \mathrm{P} \otimes 0.001)$, being hurt/cut by others $(\mathrm{OR}=26.757, \mathrm{P} \otimes 0.001)$, and being struck by an object ( $O R=15.345, P \otimes 0.001)$ were stronger independent risk factors for open fracture than low fall; moreover, lower limb fracture (OR=5.970, $P \otimes 0.001)$, upper limb fracture $(O R=5.865, P \bowtie 0.001)$ and multiple fractures $(\mathrm{OR}=5.414, \mathrm{P} \otimes 0.001)$ were stronger independent risk factors for open fracture than craniofacial fractures (Table 4).

\section{Discussion}

Consistent with previous studies showing that most cases of paediatric open fractures are a result of high-velocity trauma, including motor accidents and falls from a height ${ }^{20}$, the most common aetiologies in the current study were MVCs (45.6\%), being injured by a machine (13.1\%) and high fall $(11.2 \%)$. Open fractures are more common in boys (71.8\%). Most open fractures involve the forearm and tibia. In a retrospective multicentric analysis of paediatric fractures, researchers reported that $34 \%$ of open fractures involved the tibia/fibula and $32 \%$ involved the forearm, followed by the hand $(10 \%)$, femur $(6.7 \%)$ and humerus (6.5\%) [21]. In the current study, the most common open fracture sites were the tibia (31.6\%), 
fibula (22.8\%), radius (13.6\%), ulna (13.1\%) and humerus (13.1\%). We believe that the pattern of traumatic fractures among children is partly explained by differences in the activity patterns of children.

Children around the world are routinely engaged in paid and unpaid forms of work that are not harmful to them. However, they are classified as child labourers when they are either too young to work or are involved in hazardous activities that may compromise their physical, mental, social or educational development. In China, child labor refers to children or young workers under the age of 16 . In the current study, one person (6.7\%) was injured by a machine during working in the 0-16 age group. Two person (2.9\%) was struck by object during working in the 6-16 age group. We presume that the main causes of child labour are high level poverty and lack of access to good education. In the current study, nine persons (24.3\%) was cut by others in the 6-16 age group, 15 persons (40.5\%) were cut by others in the 16-18 age group. We should tighten up law enforcement to crack down on all kinds of violations and protect the children.

The frequencies of $\mathrm{NI}$ and ASOls in the patients who presented with traumatic open fractures were significantly higher than those in the patients without open fractures. The hospital stays and fees for surgical treatment in the patients who presented with traumatic open fractures were significantly higher than those in the other patients without open fractures. Therefore, it is clear that open fracture was an important associated with high frequencies of ASOls and high hospital costs. The similarities and differences between managing open fractures for younger patients and older patients have been investigated in previous studies ${ }^{22-26}$. Further research may help to identify and take preventive measures to reduce the number of open fractures, treatment costs and patient distress.

In the current study, univariate logistic regression analysis indicated that aetiologies and fracture sites were risk factors for open fractures. Multivariate logistic regression analysis indicated that mechanical trauma, being hurt/cut by others, and being struck by an object were independent risk factors for open fracture. Multivariate logistic regression analysis indicated that lower/upper limb fractures and multiple fractures were independent risk factors for open fractures. Therefore, we should maintain and enhance a safe work environment for younger adolescents and provide a safe and comfortable place for children to rest and play to avoid mechanical trauma and being struck by objects. We should also strengthen schoolbased moral education to effectively prevent crimes such as being hurt/cut by others.

\section{Abbreviations}

CT: computed tomography; MRI: magnetic resonance imaging; MVCs: motor vehicle collisions; TULFs: traumatic upper limb fractures; TLLFs: traumatic lower limb fractures; Nis: nerve injuries; ASOIs: associated injuries; SD: standard deviation.

\section{Declarations}

\section{Funding}


This work was supported by the Liaoning Provincial Natural Science Foundation of China (2019-ZD1032) and the Foundation of State Key Laboratory of Robotics (2017-001).

\section{Availability of data and material}

The datasets used and analysed during the current study are available from the corresponding author on reasonable request.

\section{Authors' contributions}

All authors contributed to the study conception and design. Material preparation, data collection and analysis were performed by Jun Liu, Deluo Wu, Lan Ou. The first draft of the manuscript was written by Hongwei Wang and all authors commented on previous versions of the manuscript. All authors read and approved the final manuscript.

\section{Ethics approval and consent to participate}

The procedure was approved by the ethics committee of Xinqiao Hospital, and patients provided written informed consent to participate in this study.

\section{Consent for publication}

Not applicable.

\section{Competing interests}

All listed authors have made substantial contributions to the manuscript and do not have any conflicts of interest.

\section{Acknowledgements}

This work was supported by the Liaoning Provincial Natural Science Foundation of China (2019-ZD1032) and the Foundation of State Key Laboratory of Robotics (2017-001).

\section{References}

1. Jones G, Cooley HM. Symptomatic fracture incidence in those under 50 years of age in southern Tasmania. J Paediatr Child Health. 2002;38(3):278-283.

2. Mattila V, Parkkari J, Kannus P, Rimpelä A. Occurrence and risk factors of unintentional injuries among 12- to 18-year-old Finns-a survey of 8219 adolescents. Eur J Epidemiol. 2004;19(5):437-444.

3. Wang H, Feng C, Liu H, Liu J, Ou L, Yu H, et al. Epidemiologic Features of Traumatic Fractures in Children and Adolescents: A 9-Year Retrospective Study. Biomed Res Int. 2019:8019063.

4. Wang H, Zhou Y, Liu J, Ou L, Zhao Y, Han J, et al. Traumatic fractures as a result of motor vehicle collisions in children and adolescents. Int Orthop. 2018;42(3):625-630. 
5. Wang H, Yu H, Zhou Y, Li C, Liu J, Ou L, et al. Traumatic fractures as a result of falls in children and adolescents: A retrospective observational study. Medicine (Baltimore). 2017;96(37):e7879.

6. Lyons RA, Sellstrom E, Delahunty AM, Loeb M, Varilo S. Incidence and cause of fractures in European districts. Arch Dis Child. 2000;82(6):452-455.

7. Spady DW, Saunders DL, Schopflocher DP, Svenson LW. Patterns of injury in children: a populationbased approach. Pediatrics. 2004;113:522-529.

8. Moon RJ, Harvey NC, Curtis EM, de Vries F, van Staa T, Cooper C. Ethnic and geographic variations in the epidemiology of childhood fractures in the United Kingdom. Bone. 2016;85:9-14.

9. Curtis EM, van der Velde R, Moon RJ, van den Bergh JP, Geusens P, de Vries F, et al. Epidemiology of fractures in the United Kingdom 1988-2012: Variation with age, sex, geography, ethnicity and socioeconomic status. Bone. 2016;87:19-26.

10. Halawa EF, Barakat A, Rizk HI, Moawad EM. Epidemiology of non-fatal injuries among Egyptian children: a community-based cross-sectional survey. BMC Public Health. 2015;15:1248.

11. Brudvik C, Hove LM. Childhood fractures in Bergen, Norway: identifying high-risk groups and activities. J Pediatr Orthop. 2003;23(5):629-634.

12. Cooper C, Dennison EM, Leufkens HG, Bishop N, van Staa TP. Epidemiology of childhood fractures in Britain: a study using the general practice research database. J Bone Miner Res. 2004;19(12):19761981.

13. Lempesis V, Rosengren BE, Nilsson JÅ, Landin L, Tiderius CJ, Karlsson MK. Time trends in pediatric fracture incidence in Sweden during the period 1950-2006. Acta Orthop. 2017;88(4):440-445.

14. Naranje SM, Erali RA, Warner WC Jr, Sawyer JR, Kelly DM. Epidemiology of Pediatric Fractures Presenting to Emergency Departments in the United States. J Pediatr Orthop. 2016;36(4):e45-8.

15. Sharma A, Gupta V, Shashikant K. Optimizing Management of Open Fractures in Children. Indian J Orthop. 2018;52(5):470-480.

16. Cheng JC1, Shen WY. Limb fracture pattern in different pediatric age groups: a study of 3,350 children. J Orthop Trauma. 1993;7(1):15-22.

17. Buckley SL, Gotschall C, Robertson W Jr, Sturm P, Tosi L, Thomas M, et al. The relationships of skeletal injuries with trauma score, injury severity score, length of hospital stay, hospital charges, and mortality in children admitted to a regional pediatric trauma center. J Pediatr Orthop. 1994;14(4):44953.

18. Rennie L, Court-Brown CM, Mok JY, Beattie TF. The epidemiology of fractures in children. Injury. 2007;38(8):913-22.

19. Tandon T, Shaik M, Modi N. Paediatric trauma epidemiology in an urban scenario in India. J Orthop Surg (Hong Kong). 2007;15(1):41-5.

20. Stewart DG, Kay RM, Skaggs DL. Open fractures in children. Principles of evaluation and management. J Bone Joint Surg Am.2005;87(12):2784-98. 
21. Skaggs DL, Friend L, Alman B, Chambers HG, Schmitz M, Leake B, et al. The effect of surgical delay on acute infection following 554 open fractures in children. J Bone Joint Surg Am. 2005;87(1):8-12.

22. Khadim MF, Emam A, Wright TC, Chapman TWL, Khan U. A comparison between the Major Trauma Centre management of complex open lower limb fractures in children and the elderly. Injury. 2019;50(7):1376-1381.

23. Nandra RS, Wu F, Gaffey A, Bache CE. The management of open tibial fractures in children: a retrospective case series of eight years' experience of 61 cases at a paediatric specialist centre. Bone Joint J. 2017;99-B(4):544-553.

24. Talbot C, Davis N, Majid I, Young M, Bouamra O, Lecky FE, et al. Fractures of the femoral shaft in children: national epidemiology and treatment trends in England following activation of major trauma networks. Bone Joint J. 2018;100-B(1):109-118.

25. Young K, Aquilina A, Chesser TJS, Costa ML, Hettiaratchy S, Kelly MB, et al. Open tibial fractures in major trauma centres: A national prospective cohort study of current practice. Injury. 2019;50(2):497502.

26. Wuarin L, Gonzalez Al, Zingg M, Belinga P, Hoffmeyer P, Peter R, et al. Clinical and radiographic predictors of acute compartment syndrome in the treatment of tibial shaft fractures: a retrospective cohort study. BMC Musculoskelet Disord. 2020;21(1):25.

\section{Tables}

\section{Table 1 Univariate analysis of risk factors for open fracture}




\begin{tabular}{|c|c|c|c|c|c|}
\hline & Total & OF & No-OF & $c^{2}$ & $P$ \\
\hline Total & 2418 & 206 & 2212 & & \\
\hline \multicolumn{6}{|l|}{ Gender } \\
\hline Male & $1789(74.0)$ & 148(71.8) & $1641(74.2)$ & \multirow[t]{2}{*}{0.537} & \multirow[t]{2}{*}{0.464} \\
\hline Female & $629(26.0)$ & $58(28.2)$ & $571(25.8)$ & & \\
\hline \multicolumn{6}{|l|}{ Age ranges } \\
\hline $0-6$ & $550(22.7)$ & $45(21.8)$ & $505(22.8)$ & \multirow[t]{3}{*}{3.448} & \multirow[t]{3}{*}{0.178} \\
\hline $6-12$ & $764(31.6)$ & $55(26.7)$ & $709(32.1)$ & & \\
\hline $12-18$ & $1104(45.7)$ & 106(51.5) & $998(45.1)$ & & \\
\hline \multicolumn{6}{|l|}{ Seasons } \\
\hline Spring & $608(25.1)$ & $49(23.8)$ & $559(25.3)$ & \multirow[t]{4}{*}{0.354} & \multirow[t]{4}{*}{0.949} \\
\hline Summer & $657(27.2)$ & $59(28.6)$ & $598(27.0)$ & & \\
\hline Autumn & $629(26.0)$ & $53(25.7)$ & $576(26.0)$ & & \\
\hline Winter & $524(21.7)$ & $45(21.8)$ & $479(21.7)$ & & \\
\hline \multicolumn{6}{|l|}{ Etiologies } \\
\hline MVCs & $713(29.5)$ & $94(45.6)$ & $619(28.0)$ & \multirow[t]{7}{*}{256.556} & \multirow[t]{7}{*}{$\llbracket 0.001$} \\
\hline Wounded by machine & $48(2.0)$ & $27(13.1)$ & $21(0.9)$ & & \\
\hline High fall ( $\geq 2 m)$ & $348(14.4)$ & $23(11.2)$ & $325(14.7)$ & & \\
\hline Low fall ( $(02 m)$ & $1027(42.5)$ & $21(10.2)$ & $1006(45.5)$ & & \\
\hline Struck by object & $101(4.2)$ & $20(9.7)$ & $81(3.7)$ & & \\
\hline Hurt/cut by others & $74(3.1)$ & $17(8.3)$ & $57(2.6)$ & & \\
\hline Others & $107(4.4)$ & $4(1.9)$ & $103(4.7)$ & & \\
\hline \multicolumn{6}{|l|}{ Fracture site } \\
\hline LLFs & $758(31.3)$ & $90(43.7)$ & $668(30.2)$ & \multirow[t]{6}{*}{42.384} & \multirow[t]{6}{*}{$\nabla 0.001$} \\
\hline ULFs & $940(38.9)$ & $75(36.4)$ & $865(39.1)$ & & \\
\hline CFFs & $427(17.7)$ & $13(6.3)$ & $414(18.7)$ & & \\
\hline SFs & $78(3.2)$ & $0(0)$ & $78(3.5)$ & & \\
\hline RSFs & $8(0.3)$ & $0(0)$ & $8(0.4)$ & & \\
\hline MFs & 207(8.6) & $28(13.6)$ & 179(8.1) & & \\
\hline
\end{tabular}


ULF: upper limb fracture; LLF: lower limb fracture; CFF: craniofacial fracture; SF: spinal fracture; RSF: fracture of rib and sternum; MF: multiple fracture

Table 2 Fractures wounded by machine, hurt/cut by others, struck by object

\begin{tabular}{|c|c|c|c|}
\hline Age groups & & $0-16$ & $16-18$ \\
\hline \multirow[t]{6}{*}{ Wounded by machine } & Total & 15 & 33 \\
\hline & Male/ Female & $8 / 7$ & $32 / 1$ \\
\hline & Wound environment & & \\
\hline & Playing & 14(93.3\%) & $1(3.0 \%)$ \\
\hline & Working & $1(6.7 \%)$ & $30(90.9 \%)$ \\
\hline & Daily life & 0 & $2(6.1 \%)$ \\
\hline \multirow[t]{6}{*}{ Struck by object } & Total & 70 & 31 \\
\hline & Male/ Female & $58 / 12$ & $30 / 1$ \\
\hline & Wound environment & & \\
\hline & Playing & $37(52.9 \%)$ & $11(35.5 \%)$ \\
\hline & Working & $2(2.9 \%)$ & $20(64.5 \%)$ \\
\hline & Daily life & $31(44.3 \%)$ & 0 \\
\hline \multirow[t]{6}{*}{ Hurt/cut by others } & Total & 37 & 37 \\
\hline & Male/ Female & $34 / 3$ & $34 / 3$ \\
\hline & Mechanism & & \\
\hline & Hurt by others & $19(51.4 \%)$ & $18(48.6 \%)$ \\
\hline & Hurt by blunt object & $9(24.3 \%)$ & $4(10.8 \%)$ \\
\hline & Cut by others & $9(24.3 \%)$ & $15(40.5 \%)$ \\
\hline
\end{tabular}

Table 3 Hospital indexes for traumatic open fractures in children and adolescents 


\begin{tabular}{|lllll|}
\hline & OF & No-OF & $c^{2}$ or $Z$ & $P$ \\
\hline Total & 206 & 2212 & & \\
\hline Age & $13(7 \sim 14)$ & $12(7 \sim 16)$ & -2.258 & 0.024 \\
\hline NI & $53(25.7 \%)$ & $409(18.5 \%)$ & 6.388 & 0.011 \\
\hline ASOls & $88(42.7 \%)$ & $557(25.2 \%)$ & 29.633 & $\varangle 0.001$ \\
\hline Treatment ST/CT & $181 / 25$ & $1596 / 616$ & 23.880 & $\varangle 0.001$ \\
\hline Complications-ST & $12 / 181$ & $153 / 1596$ & 1.687 & 0.194 \\
\hline Complications-CT & $5 / 25$ & $27 / 616$ & 12.354 & $\varangle 0.001$ \\
\hline ICU stays-ST & $1.0(0.0 \sim 4.5)$ & $1.0(0.0 \sim 3.0)$ & -0.550 & 0.602 \\
\hline ICU stays-CT & $8.0(5.0 \sim 13.5)$ & $7.0(3.0 \sim 13.0)$ & -0.431 & 0.667 \\
\hline Hospital stays-ST & $17.0(9.0 \sim 29.0)$ & $11.0(8.0 \sim 17.0)$ & -5.418 & $\varangle 0.001$ \\
\hline Hospital stays-CT & $0.0(0.0 \sim 1.0)$ & $0.0(0.0 \sim 1.0)$ & -1.150 & 0.250 \\
\hline Hospital fees-ST & 33261.4 & 24017.2 & -3.163 & 0.002 \\
& $(19564.8 \sim 49375.7)$ & $(14594.5 \sim 42346.1)$ & & \\
\hline Hospital fees-CT & 4812.6 & 4074.2 & -1.236 & 0.216 \\
& $(2964.4 \sim 8124.0)$ & $(1902.3 \sim 7691.1)$ & & \\
\hline
\end{tabular}

ASOIs: associated injuries; NI: nerve injury; ICU: intensive care unit; ST: surgical treatment; CT: conservative treatment

Table 4 Multivariate analysis of risk factors for open fracture 


\begin{tabular}{|c|c|c|c|c|}
\hline & \multirow[t]{2}{*}{$P$} & \multirow[t]{2}{*}{ OR } & \multicolumn{2}{|l|}{$95 \%$ OR } \\
\hline & & & Lower & Upper \\
\hline \multicolumn{5}{|l|}{ Etiologies } \\
\hline MVCs & $\triangle 0.001$ & 8.802 & 5.141 & 15.071 \\
\hline Wounded by machine & $\otimes 0.001$ & 64.229 & 30.731 & 134.24 \\
\hline High fall $(\geq 2 m)$ & $\otimes 0.001$ & 4.670 & 2.455 & 8.885 \\
\hline Struck by object & $₫ 0.001$ & 15.345 & 7.763 & 30.333 \\
\hline Hurt/cut by others & $₫ 0.001$ & 26.757 & 12.598 & 56.829 \\
\hline Others & 0.289 & 1.819 & 0.601 & 5.503 \\
\hline Low fall (प2m) & - & - & - & - \\
\hline \multicolumn{5}{|l|}{ Fracture site } \\
\hline LLFs & $\varangle 0.001$ & 5.970 & 3.196 & 11.150 \\
\hline ULFs & $\varangle 0.001$ & 5.865 & 3.069 & 11.211 \\
\hline SFs & 0.997 & 0.000 & 0.000 & - \\
\hline RSFs & 0.999 & 0.000 & 0.000 & - \\
\hline MFs & $₫ 0.001$ & 5.414 & 2.657 & 11.030 \\
\hline CFFs & - & - & - & - \\
\hline
\end{tabular}

ULF: upper limb fracture; LLF: lower limb fracture; CFF: craniofacial fracture; SF: spinal fracture; RSF: fracture of rib and sternum; MF: multiple fracture 